\title{
PENATAAN KAWASAN PULAU MANSINAM SEBAGAI OBYEK WISATA ALAM DI TELUK DORERI KABUPATEN MANOKWARI PROPINSI PAPUA BARAT
}

\author{
Fransina Albya Agapa**) dan A. A Sagung Alit Widyastuty*)
}

\begin{abstract}
Abstrak
Perkembangan pariwisata sudah sedemikian pesat dan terjadi suatu fenomena yang sangat global dengan melibatkan jutaan manusia, baik di kalangan masyarakat, industri pariwisata maupun kalangan pemerintah. Oleh karena itu pariwisata perlu ditata secara berkelanjutan. Pariwisata di Indonesia sudah termasuk dalam sektor ekonomi yang penting bahkan dapat diharapkan sebagai penghasil devisa utama. Kawasan pesisir pantai merupakan obyek yang sangat diminati para wisatawan baik lokal maupun regional.

Tujuan penelitian ini adalah untuk menentukan faktor yang mempengaruhi minat dan jumlah pengunjung, sarana dan prasarana, serta konsep penataan dalam mendukung program wisata alam di Pulau Mansinam.

Penelitian ini menggunakan analisis SWOT dengan mtode teknik wawancara dan kuesioner. Hasil penelitian dengan analisis SWOT menunjukan bahwa obyek wisata Pulau Mansinam sangat berpeluang atau mempunyai prospek kekuatan yang dapat ditata untuk di kembangkan guna meningkatkan ekonomi daerah.
\end{abstract}

Kata Kunci : Penataan kawasan, Pembangunan Berkelanjutan, SWOT

\section{PENDAHULUAN \\ LatarBelakang}

Pariwisata merupakan salahsatu industri yang sudah berkembangan dengan pesat dan terjadi suatu fenomena yang sangat global melibatkan jutaan manusia, baik di kalangan masyarakat, maupun kalangan pemerintah. Pariwisata di Indonesia sudah termasuk dalam sektor ekonomi sebagai - penghasil devisa utama. Kebijakan pemerintah terhadap pengembangan pariwistata adalah undangundang No.10 Tahun 2009 tentang Kepariwisataan, undang-undang No.26 Tahun 2007 tentang Penataan Ruang.

Kabupaten manokwari memiliki sejumlah obyek wisata yang cukup potensial dalam hal ini wisata Pulau Mansinam di pesisir selatan yang lokasinya berada di teluk Doreri, yang mempunyai potensi alam berupa panorama alam pantai yang indah dan menarik, pantai dengan pasir putih yang panjang dan luas. Adapun potesi sejarah/cagar budaya berupa gereja tua, sumur tua, tugu peringatan dan berbagai tarian tradisioanal.

Keragaman daya tarik kurang beragam masih alami dan belum tersedia sarana dan prasarana yang dapa Dengan melihat potensi yang ada Keragaman daya tarik kurang beragam masih alami dan belum tersedia sarana dan prasarana yang dapat menunjang pariwisata pada obyek wisata Pulau Mansinam.
Karena itu perlu adanya perencanaan pengembangan obyek wisata lebih lanjut baik yang melihat semua potensi yang ada di lingkungan sendiri maupun faktor lingkungan eksternal yang ada, untuk peningkatan obyek dan daya tarik wisata baik berupa peningkatan jumlah sarana prasarana penunjang pariwisata maupun peningkatan atraksi dan daya tarik wisata sehingga diharapkan dapat menarik kedatangan wisatawan agar dapat memberikan keuntungan bagi pemasukan pendapatan daerah dalam sektor pariwisata.

\section{Lokasi Penelitian}

Loksi studi yang menjadi titik survey adalah kawasan obyek wisata Pulau Mansinam yang terletak di teluk Doreri sebelah selatan kota manokwari yang memiliki luas $\pm 410,97 \mathrm{Ha}$.

\section{Perumusan Masalah}

1. Faktor-faktor apa yang mempengaruhi minat dan jumlah pengunjung di pulau Mansinam. Sebagai obyek wisata alam.

2. Sejauhmana kondisi sarana dan parasarana di Pulau Mansinam

3. Bagaimana konsep penataan kawasan Pulau Mansinam sebagai alam.

\footnotetext{
**) Mahasiswa PWK

*) Dosen PWK Universitas PGRI Adi Buana Surabaya
} 


\section{Tujuan dan Manfaat}

1. Menentukan faktor-faktor potensi yang ada di Pulau Mansinam.

2. Menentukan keadaan sarana dan prasarana dalam mendukung program wisata alam di Pulau Mansinam.

3. Menentukan konsep penataan kawasan Pulau Mansinam sebagai wisata alam.

\section{KAJIAN PUSTAKA}

Batasan dan Pengertian Pengembangan Pariwisata

Berdasarkan UU RI No. 10 Tahun

2009 tentang Kepariwisataan, pengertian pariwisata adalah segala sesuatu yang berhubungan dengan wisata, termasuk pengusahaan objek/daya tarik wisata, serta usaha-usaha yang terkait dengan bidang tersebut.

Pariwisata pada dasarnya mengandung 5 (lima) unsur, yaitu:

1. Unsur manusia (wisatawan)

2. Kegiatan (perjalanan)

3. Motivasi (menikmati)

4. Sasaran (objek dan daya tarik wisata)

5. Usaha (jasa pariwisata)

Pengembangan pariwisata berarti pertumbuhan. Pertumbuhan berarti ruang untuk perluasan. Pada pengembangan pariwisata terdapat penawaran dan permintaan. Penawaran adalah unsur-unsur daya tarik wisata pada sarana prasaran pnunjang, sarana prasarana transportasi, sumberdaya kebudayaan. Permintaan adalah kegiatan pariwisata yang dapat di harapkan pada fasilitas rekreasi yaitu transportasi, penginapan rumah makan, wc, promosi.

\section{Konsep Tentang Potensi Dan Daya Tarik Wisata}

Pendit (1999: 21) menerangkan bahwa potensi wisata adalah berbagai sumber daya yang terdapat di sebuah daerah tertentu yang bisa dikembangkan menjadi atraksi wisata. Daya Tarik Wisata menurut Undang-undang Republik Indonesia No. 10 tahun 2009 tentang Kepariwisataan Bab I, pasal 5, menyebutkan sebagai berikut "daya tarik wisata" adalah segala sesuatu yang memiliki keunikan, keindahan, dan nilai yang berupa keanekaragaman kekayan alam, budaya dan hasil buatan manusia yang menjadi sasaran.

\section{Konsep Pembagunan Pariwisata Berkelanjutan \\ Pada konsep pembangunan berkelanjutan yaitu di lakukan langkah-}

langkah oleh pemerintan untuk menindak lanjuti pembangunan khususnya di bidang pariwisata. Periwisata berkelanjutan menurut muller adalah meningkatkan kesejahteraan, perekonomian dan kesehatan.konsep pembangunan pariwisata menurut Natori adalah terpelihara mutu, meningkatkan kesejahteraan , mewujudkan keeimbangan,dan kesejahteraan. Undang undang Pariwisata menurut PERDA Kabupaten Manokwari

1. UU No 18 tahun 2006 tentang Rtribusi izin usaha kepariwisataan

2. UU No 23 Tahun 2003 Tentang Retribusi Izin Usaha Rekreasi Hiburan mum.

3. UU No 21 Tahun 2003 Tentang Retribusi Izin Usaha Sarana Pariwisata

\section{Analisis SWOT}

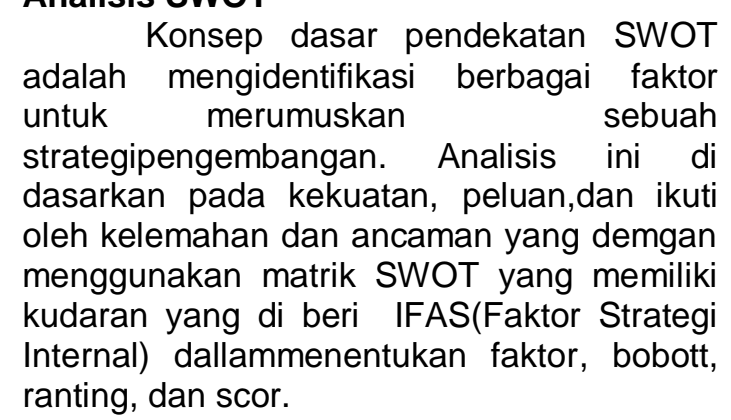

\section{METODE PENELITIAN \\ Tempat dan Waktu}

Penelitian ini dilaksanakan pada obyek wisata pulau mansinam yang terdapat di kota Manokwari yang berlangsung dari tanggal 1 september sampai 30 september 2011.

\section{Objek}

Objek yang diamati adalah wisata pulau mansinam Dengan potensi yang dimiliki pada kota Manokwari

\section{Metode Penelitian}

Metode yang digunakan dalam penelitian ini adalah metode studi kasus dengan teknik pengambilan data yaitu teknik observasi dan wawancara. Pengambilan data dilakukan dengan sensus terhadap obyek wisata pulau Mansianam yang ada di kota Manokwari.

\section{Metode Pengumpulan Data}

Data yang dikumpulkan dalam penelitian ini adalah data primer dan data sekunder dengan populasi dan sampel.

Metode Analisis Data

- kuantitatif 
Analisis sarana dan prasaranapada kebutuhan tran[portasi jaringan jalan dan dermaga dan kebutuhan wisata pada perdagangan,penginapan,rumah makan, wc/toilet dan promosi.

- Analisis potensi pada analisis ini yang di lihat adah potensi sumberdaya alam pada pemandangan alam pantai pulau mansinam dana juga pada tarian tradisional(tari magas/ular, tari yospan, tari panah/perang) begitupulah pada cagar budaya(gereja, sumur tua,tugu)

- Analisis SWOT

Metode yang digunakan adalah Analisis SWOT, dimana metode ini digunakan untuk menganalisa pengembangan obyek wisata di pulau mansinam, masingmasing dengan mengidentifikasi kekuatan (strengths), kelemahan (weaknesses), kesempatan opportunies, serta ancaman (treahs) pada obyek penelitlan.

\section{GAMBARAN UMUM WILAYAH PENELITIAN \\ Gambaran Wilayah Kabupaten \\ Kondisi Fisik Dasar}

Kabupaten Manokwarindustri ini memiliki luas $37.901 \mathrm{~km} 2$ dengan 0.015'3,025 LS dan 132,035'- 134,045 BT yang berbatasan dengan samudra pasifik(u), kabupaten fak_fak(S), kabupaten sorong(B), kabupaten Numfur,Nabire,yapen waropen( $T$ ) yang memiliki wilayah datrar, bergelombang dan dan bergunung.,yang jenis tanahnya pada umumnya tanah kapur merahan, tanah endapan aluval dengan iklim tropis yang dimana manokwari merupakan kawasan dataran tinggi yang di kelilingi oleh aliran sungai sungai bermuara pada samudara pasifik. Peanduduk yang berdomisili dikabupaten manokwari sebanyak 167.537 jiwa menurut data tahun 2010, padatnya penduduk di kotamanokwari beradapada manokwari barat daengan jumlah kepadatan 31.189 jiwa yang terdiri dari suku besar arfak, suku wamesa, suku samuru, suku sebyar, suku iraruto dan suku numfor doreri dan yang berlatar belakang agama, yang paling dominan adalah agama kristen dengan jumlah 21.914 jiwa.

\section{Kondisi Fisik Binaan}

Dalam menunjang pariwisata pada suatu obyek wisata maka kota manokwari memiliki fasilitas (kesehatan, perdagangan dan jasa, bank, hiburan dan olah raga, peribadatan) dan memiliki utilitas(prasarana jalan, prasarana listrik, prasarana airbersih) dan transportasi(darat, laut, udara).

\section{Kondisi sarana prasarana pendukung pariwisata di kabupaten manokwari.}

Untuk mendukung peningkatan pariwisata maka di butuhkan sarana dan fasilitas penunjang di antaranya akomodasi, rumah makan,sarana transportasi, prasarana telekomunikasi seni dan budaya dimana memiliki senjata tradisional(anak panah), alat musik(tifa), anyaman( gelang,kaling,tas, gantungan kunci ini smua merupakan hasil seni masyarakat kabupaten Manokwari.

\section{Gambaran Wilayah Penelitian}

Wilaya peneliti ini ada kawan obyek wisata Pulau mansinam yang terletak di teluk Doreri manokwari selatan,dengan luas 410,97 hektar yang memiliki potensi obyek wisata alam, tarian dan cagar budaya. Pada kondisi fisik dasara din lihat dari kondisi lingkungan yang di miliki obyek wisata dalam mendukung wisata yaitu topografi $d$ dan vegetasi yang sangat mendukung. Kondisi ini segala yang ada di obyek wisata di lihat dari penduduk, pendidikan, kesehatan, sosial budaya.

\section{Potensi pada obyek wisata}

a. Sumberdaya alam yaitu keinahan pantai dengan pasirputih yang luas dan panjang,airnya jernih kebiruan.

b. Sumberdaya Manusia dilihat dari tarian tradisional(tari magas/ ular, tari yospan,tari panah/ perang) dan memiliki agar budaya(gereja, sumur, tugu

\section{Karakteristik pengunjung}

Pada karakteristk ini di lihat dari karakteristik berdasarkan umur, asal, tujuan. Kondisi sarana prasarana pada obyekwisata sangat di sayangkan karena masih sangat minim penyediaan nya seperti wc/toilet, dan dermaga belum memaddai dan sarana(penginapan, rumah makan, toko/souveni) pendukung lainnya berada di kota Manokwari, untuk kondisi alam cukup memadai.

Dalam pariwisata sangatlah di butuhkan yaitu infrastruktur untuk mendukung suatu pariwisata dalam hal ini di lihat dari pengguna dermaga, jalan, dan MCK Yang di rasakan belum makisimal. Hal ini di sebabkan dari beberapa Faktor yang membuat orang untuk menggunakan dermaga, jalan, dan MCK pada kawasan pariwisata tersebut. Faktor -faktor tersebut antara lain kenyamanan,keselamatan, dan 
Fransina Albya Agapa \& A.A. Sagung Alit Widyastuty : Penataan Kawasan Pulau Mansinam Sebagai Obyek Wisata Alam Di Teluk Doreri Kabupaten Manokwari Propinsi Papua Barat

keamanan. Untuk lebih detail pembahasan ini akan di jabarkan sesuai dengan infrastruktur yang ada yaitu dermaga, jalan,

\subsection{Dermaga pada kawasan pulau mansinam}

\section{Kondisi eksisting}

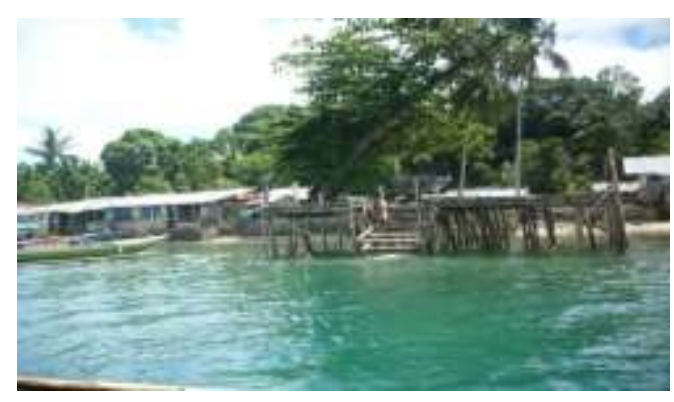

\section{Kondisi eksisting}

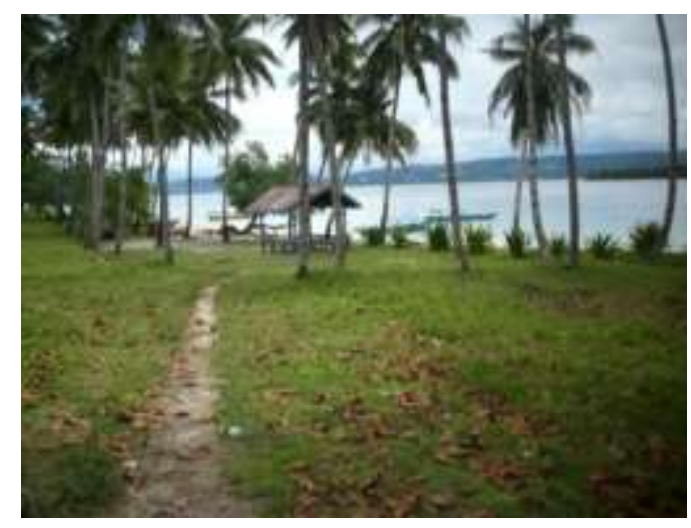

dan MCK

Mansinam

pada lokasi pariwisata Pulau Kabupaten Manokwari.

\section{Analisis}

1. Dermaga yang terbuat dari kayu dimana kaki dermaga yang sudah hamir lapuk sehingga kurang nyaman untuk menggunakan.

2. Kondisi keamanan yang rendah karenan badan dermaga yang penyusunannya jarang-jarang sehingga perlu hati-hati dalam menggunakan dermaga tersebut.

3. Anak tangga dermaga yang sudsh bolong-bolong sehingga kurang aman saat menggunakannya.

\section{Analisis}

1. Jalan pada lokasi ariwisata belum maksimal atau masih alami tanah bercamur pasir yang akibatnya tumbuhi rumut di sekitar jalan.

2. Gasebo yang tersediaun belum maksimal sehingga ara engunjung kebanyakan tidak menggunakan gasebo tersebut

3. jalan sekitar obyek wisata pulau mansinam masih alami dan belum tersedianya MCK sehingga para pengunjung tidak nyaman dan aman pada obyek wisata pulau mansinam. 


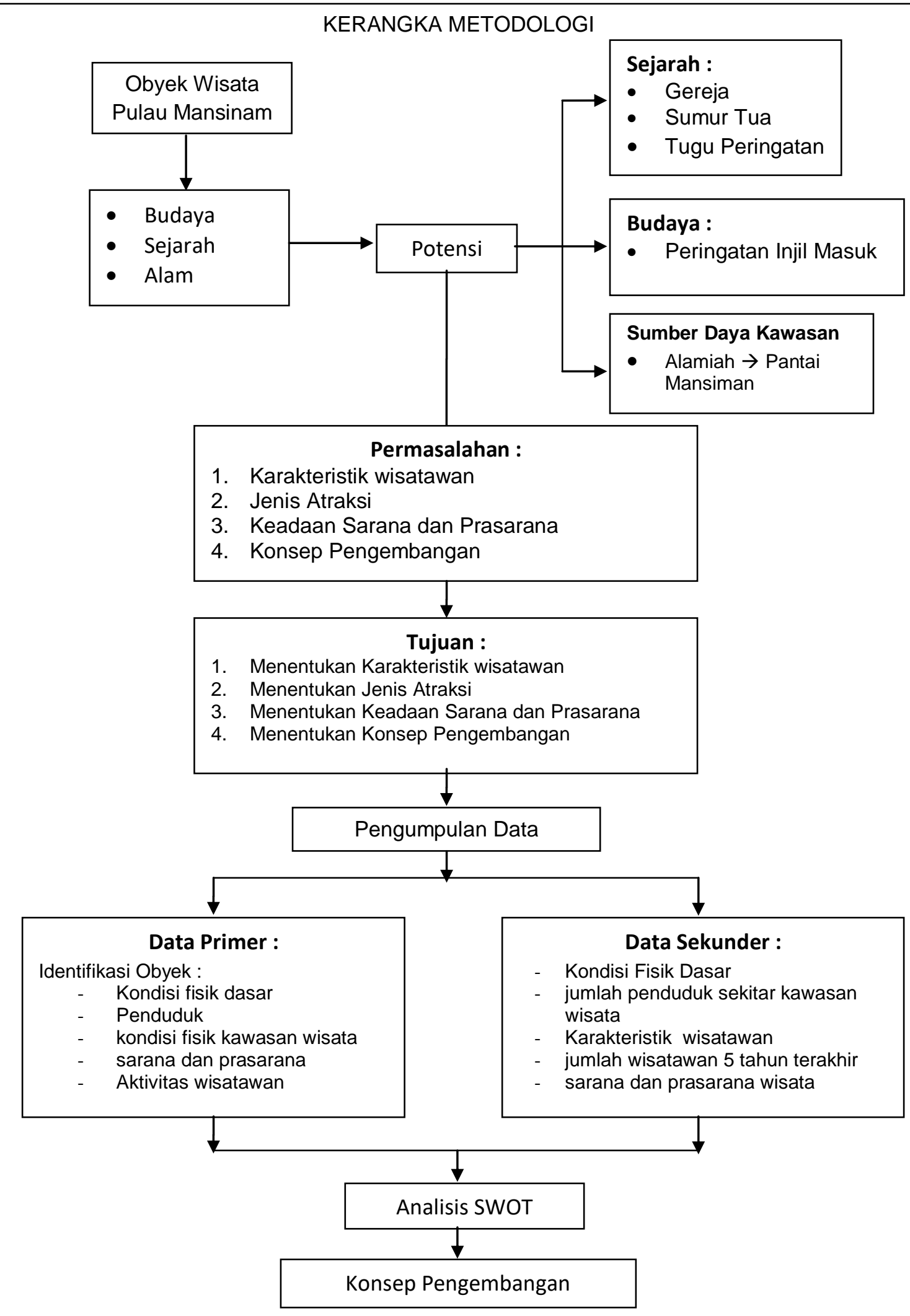

Gambar 1. Kerangka Metodologi

Sumber : Hasil Pemikiran, Tahun 2012 
ANALISIS

\section{Keadaan kondisi Obyek Wisata}

Pada kondisis ini di hat dara keadaan lingkungan, sarana prasarana, dan aktifitas dalam menarik wisatawan di lihata dari peran masyarakat dalam menyambut dan memberikanlayanan kepada wisatawan yang berkunjung untuk itu perlu adanya kerjasama antar pemerintah dan masyarakat dalam mendukung wisata ini. Kondisi pada lingkungan untuk keadaan flora dan fauna sangat mendukung dengan obyek ini namum belum adanya pelestarian lingkungan.

\section{Jumlah Wisatan}

Pada jumlah wisatawan yang banyak berkunjung adalah wisatawan lokal u,untuk non lokal hanya seberapa, ini akaibtnya kurang adalnya promosi.

\section{Sarana Wisataa}

Kondisi sarana(penginapan, rumah makan, toko/ souvenir) saat ini secara umum belum ada di lokasi wisata masih berada di kota manokwari.

\section{Sarana Prasarana Tranportasi}

Pada kondisi ini yang merupakan salah satu daya tari bagi wisata untukitu jalan cuup memadai namun dermaga belum memadai, untuk itu perlu adanya penataan. Akibatnya jumlah wisatawan yang berkunjung ke obyek wisata ini sangat minim begitu pulah kurang adanya informasi yang meluas untukobyek wisata ini.
Analisi Eksternal pada peluang yang bersifat positif untuk penataan untuk pengembangan dalam menarik wisatawan dilihta dari kondisi keamana dan kenyamanan agar terhindar dari hal-hal yang tidak di inginkan dan wisata dapat berlangsung dengan baik tanpa ada ancaman dari orang yang tidak di kenal dan jugan memiliki kondisi jalan yang memadai dalam mendukung obyek wisata yang diman obyek ini juga memiliki lingkungan yang asri dan alami udara yang sejuk dan nyaman,untuk itu masih memiliki kesempatan untuk menata segala yang kurang terawat dan membangun yang belum ada dalam hal ini adalah kebijakan pemerintah untuk menata di masa mendatang.

Analisis Eksternal pada ancaman faktor yang di lihat dari segi negatif pada obyek wisata terdai pencemaran lingkungan akibat pembuangan sampat dan penebangan hutansecara liar dan kondisi dermaganya belum memadai untu itu lingkup wisata masih rendah tentunya akan adanya daya saing dengan obyek wisata lainnya. Untuk menentukan analisi internal dan Eksternal di tyentukan dengan analisis kafis/kafe yaitu pembobotan, dan menentukan ranting. Dimana bobot di peroleh dar hasil survei dan wawancara sedangkan rangting dari sub instasi/pihakpengelolah.

Tabel 1. Kesimpulan Analisis Faktor Internal (KAFI)/Eksternal (KAFE) Obyek Wisata Pulau Mansinam

\begin{tabular}{|c|c|c|c|c|}
\hline No. & $\begin{array}{c}\text { Faktor-faktor Internal Strategik } \\
\text { Kekuatan (Strengths) }\end{array}$ & Bobot & Rating & Score \\
\hline 1 & $\begin{array}{l}\text { Memiliki daya tarik wisata yang dapat } \\
\text { diandalkan }\end{array}$ & 0,20 & 4 & 0,80 \\
\hline 2 & $\begin{array}{l}\text { Dapat menarik wisatawan lokal maupun } \\
\text { regional }\end{array}$ & 0,20 & 3 & 0,45 \\
\hline 3 & $\begin{array}{l}\text { Terdapat beberapa aktifitas wisata } \\
\sum_{\text {Kelemahan (Weaknesses) }}\end{array}$ & $\begin{array}{l}0,15 \\
0,55\end{array}$ & 3 & $\begin{array}{l}0,45 \\
1,70\end{array}$ \\
\hline 1 & $\begin{array}{l}\text { Karakteristik wisatawan pada Jumlah } \\
\text { wisatawan yang datang masih sedikit }\end{array}$ & 0,15 & 2 & 0,30 \\
\hline 2 & Fasilitas wisata belum tersedia & 0,10 & 3 & 0,30 \\
\hline 3 & $\begin{array}{l}\text { belum tersedianya sarana dan } \\
\text { prasarana akomodasi dan jasa wisata }\end{array}$ & 0,10 & 3 & 0,30 \\
\hline & $\sum \sum_{\text {Total }}$ & $\begin{array}{l}0,45 \\
1,00\end{array}$ & & 1,12 \\
\hline No. & $\begin{array}{l}\text { Faktor-faktor Eksternal Strategik } \\
\text { Peluang (Opportunities) }\end{array}$ & Bobot & Rating & Score \\
\hline 1 & $\begin{array}{l}\text { Kondisi keamanan (lokal dan regional) } \\
\text { cukup kondusif }\end{array}$ & 0,20 & 4 & 0,80 \\
\hline 2 & Sarana dan prasarana transportasi & 0,15 & 4 & 0,45 \\
\hline
\end{tabular}




\begin{tabular}{|c|c|c|c|c|}
\hline No. & $\begin{array}{c}\text { Faktor-faktor Internal Strategik } \\
\text { Kekuatan (Strengths) }\end{array}$ & Bobot & Rating & Score \\
\hline & cukup memadai & & & \\
\hline 3 & $\begin{array}{l}\text { Kondisi lingkungan sekitar masih asri } \\
\text { dan alami }\end{array}$ & 0,10 & 3 & 0,30 \\
\hline \multirow[t]{2}{*}{4} & $\begin{array}{l}\text { Adanya peran serta masyarakat sekitar } \\
\text { obyek wisata }\end{array}$ & 0,10 & 2 & 0,20 \\
\hline & Ancaman (Threats) $\Sigma^{\Sigma}$ & 0,55 & & 1,75 \\
\hline 1 & $\begin{array}{l}\text { Kondisi jalandan dermaga umumnya } \\
\text { belum memadai }\end{array}$ & 0,15 & 3 & 0,45 \\
\hline 2 & Sering terjadi penebangan hutan & 0,10 & 3 & 0,30 \\
\hline 3 & Fasilitas Wc belum tersedia & 0,10 & 1 & 0,10 \\
\hline 4 & $\begin{array}{l}\text { Daya saing yang masih rendah untuk } \\
\text { lingkup lokal dan regional }\end{array}$ & 0,10 & 2 & 0,20 \\
\hline & $\sum \sum_{\text {Total }}^{\breve{s}}$ & $\begin{array}{l}0,45 \\
1,00\end{array}$ & & 1,05 \\
\hline
\end{tabular}

Sumber: Hasil analisa

Adapun score yang didapat dari variabel internal dan eksternal obyek wisata Pulau Mansinam sebagai berikut :

- Internal Variabel Kekuatan (Strengths) $=1,95$

Variabel Kelemahan (Weaknesses) $=1,12$

- Eksternal :
Variabel Peluang (Opportunities) $=1,75$

Variabel Ancaman (Threats) $=1,05$

Dengan perhitungan :

$\mathrm{S}-\mathrm{W}: \mathrm{O}-\mathrm{T}$

$1,70-1,12: 1,75-1,05$

$0,58: \quad 0,70$

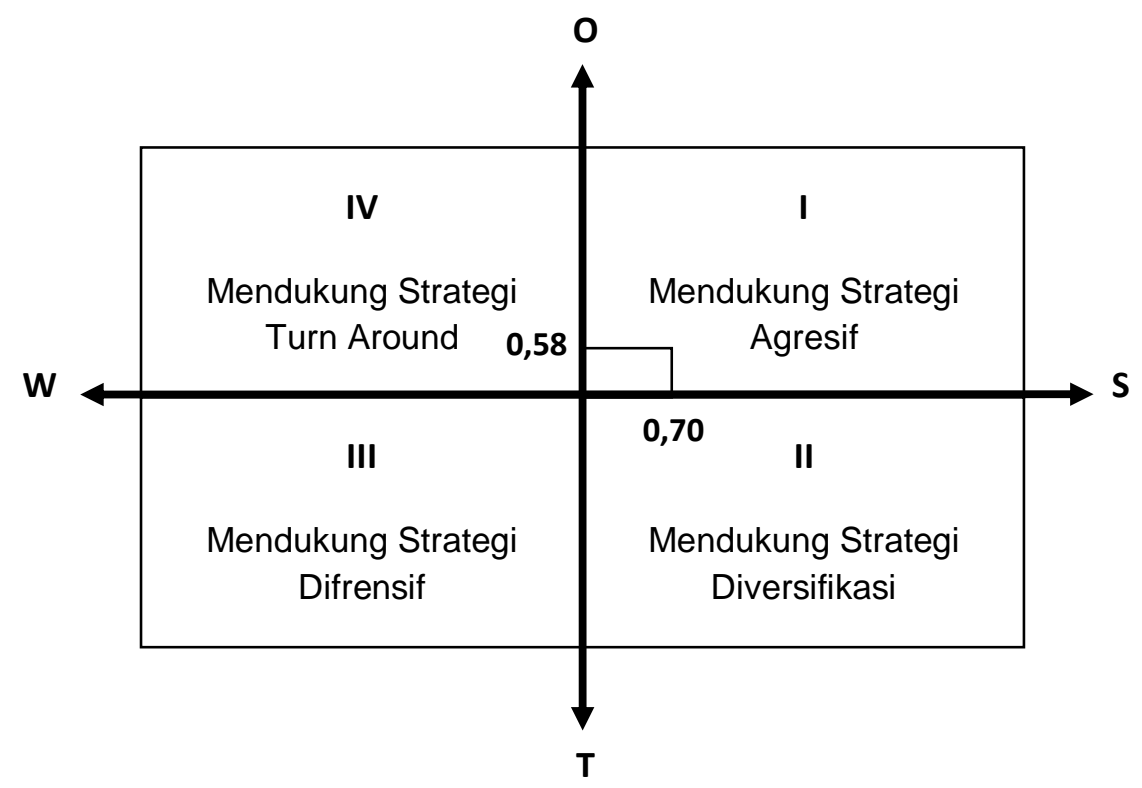

Grafik 1. Matrik SWOT Penentuan Strategi Pengembangan Obyek Wisata Pulau Mansinam Hasilnya adalah onsep penaataan dengan menggunakan kuadran 1 yang dimana mengarah pada pertumbuhan yaitu trategi agresif 
Tabel 2. Analisa SWOT dan Strategi Pengembangan Obyek Wisata Pantai Mananga Aba

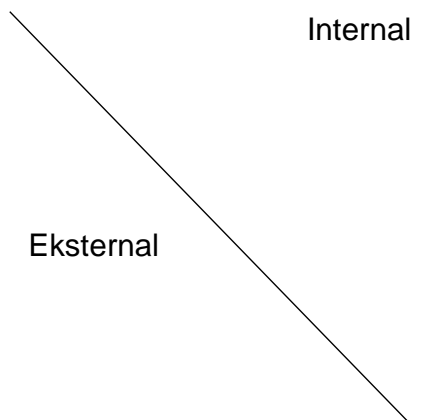

Peluang (Opportunities)

1. Kondisi keamanan (lokal dan regional) cukup kondusif.

2. Kondisi lingkungan masih alami dan asri.

3. Sarana dan prasarana transportasi cukup memadai.

4. Pariwisata dapat dikaitkan dengan pengembangan pemukiman dan kota.

Ancaman (Threats)

1. Kondisi fisik jalan umumnya belum memadai.

2. Sering terjadi kebakaran hutan.

3. Adanya aktivitas penambangan pasir.

4. Daya saing masih rendah untuk lingkup regional.
Kekuatan (Strengths) dapat diandalkan

2. Atraksi alam terumbu karang

3. Aksesibilitas jalan yang baik

4. Atraksi hutan Savanna

5. Dapat menarik wisatawan lokal maupun regional

6. Terdapat beberapa macam aktifitas wisata
1. Memiliki daya tarik wisata yang

Kelemahan (Weaknesses)

1. Jumlah wisatawan yang datang masih sedikit

2. Fasilitas wisata yang kurang memadai

3. Belum tersedianya sarana dan prasarana akomodasi dan usaha jasa wisata.

4. Pemasaran pariwisata belum kuat dan menyebar luas.

5. Kurangnya peran serta masyarakat.

Strategi W-O

Strategi $S-O$
1. Daya tarik wisata yang ada akan dapat lebih menarik jika didukung kondisi keamanan lokal dan regional yang kondusif.

2. Kelengkapan utilitas serta sarana dan prasarana dapat menarik lebih banyak wisatawan.

3. Daya tarik wisata yang ada jika didukung dengan lingkungan sekitarnya tetap terjaga.

4. Dengan adanya aktivitas wisata diharapkan adanya peran serta masyarakat sekitar.

Strategi S - T

1. Meningkat kondisi fisik jalan agar pencapaian ke lokasi wisata lebih mudah sehingga wisatawan tidak enggan datang.

2. Membuat larangan berupa peraturan daerah agar masyarakat tidak melakukan penambangan yang dapat menyebabkan erosi.

3. Menghimbau masyarakat agar tidak membakar hutan terutama pada musim kemarau yang dapat mengancam keberadaan daya tarik yang ada.

4. Daya tarik wisata yang ada dan aktivitas wisata dapat meningkat daya saing dengan obyek wisata lain.
1. Dengan kondisi keamanan (lokal dan regional) yang kondusif dapat meningkat jumlah wisatawan.

2. Dengan memadainya fasilitas, sarana dan prasarana transportasi (lokal dan regional), wisatawan dapat lebih mudah untuk datang dan berkunjung.

3. Meningkatkan dan menyebarluaskan pariwisata.

4. Memberikan kesempatan pada masyarakat sekitar untuk ikut berperan serta dalam memenuhi kebutuhan sarana dan prasarana akomodasi serta usaha jasa wisata.

Strategi W - T

1. Meningkatkan kondisi fisik jalan yang ada agar meningkatkan jumlah wisatawan.

2. Meningkatkan jumlah wisatawan dengan melengkapi kebutuhan akan fasilitas wisata.

\section{KESIMPULAN DAN SARAN Kesimpulan}

Faktor potensi yang di minati oleh wisatawan adalah keindahanpantai pada pasir putih,air yang jernih kebiruan sedangkan untuk tarian dan cagar budya adalah sebagai pendukung sedangkan kondisi sarana prasarana dalam hai ini dermaga belum tertata dengan baik, begitu pulah fasilitas penujang dalam hal ini wc/mck belum tertata denan baik untuk itu di peroleh hasil analisi swot untuk program konsep penataan untuk pengembangan. Sebagai daya tarik sesuaiptensi yang didukung oleh kondisi lingkungan yang tetap terjaga dari kerusakan dan memberikan kesempatan kepada masyarakat dalammelayani dan memenuhi kebutuhan wisatawan dan adanya kerjasama antara pemerintah dan masyarakat ,agar obyek wista ini bisa terjaga ,ditata,dan dirawat. 


\section{Saran}

Pada obyek wisata Plau u Mansinam ini seperti telah di jelasan bahwa memiliki keindaha pantai dan di dukung oleh tarian dan cagar budaya untuk itu dapat mengajak masyarakat untuk turut menjaga,merawat,memelihara lingungan sekitar agar tetap terjaga kelestariannya. Adapun belum tersedianya saran wisata dalam hai ini penginapan,rumah makan, toko/souvenir yang masih terpusat pada kota manokwari ,begitu juga fasilitas kurang memadai dermaga dan belum tersedianya Wc/mck pada obyek wisata, untuk itu perlu penataan agar dapat menarik wisatawan dan juga meningkatkan perekonomian masyarakat dan pendapatan daerah.dalam hal ini gambar berikut adalah konsep penaataan pada jalan, dermaga dan wc/mck.

\section{DAFTAR PUSTAKA}

A. Yoeti, Oka, 1996, Pengantar Ilmu Pariwisata. Bandung : Angkasa

A. Yoeti, Oka, 1997, Perencanaan Pariwisata Terpadu : Angkasa

A. Yoeti, Oka, 1997, Perencanaan dan Pengembangan Pariwisata, Jakarta : PT Pradnya Paramita

Ayris, tourism objects \& investment opportunities, edisi 2011

Hadinoto Prof.Ir. Kusudianto, 1996, Perencanaan Pengembangan Destinasi Pariwisata, Jakarta : PT UI press

Happy Marpaung, Drs, 2000, Pengetahuan Kepariwisataan : Penerbit Alfabeta

Jurnal legenda sejuta potensi, edisi 2011

Jurnal tourism office and the regional of culture, edisi 2011

Kusmayadi, Ir \& Endar Sugiarto, Ir,MM, Metodologi Penelitian Bidang Kepariwisataan, PT Gramedia, 2000

Musanef, 1995, Manajemen Usaha Pariwisata, Jakarta : Gunung Agung

Pusat Penelitian Kepariwisataan, Perencanaan Pariwisata Berkelanjutan, 1997, ITB 